May 2016: Accepted in the British Journal of Social Psychology

Running head: Acculturation in the Classroom

\title{
Minority acculturation and peer rejection: Costs of acculturation misfit with peer group norms
}

Laura Celeste $^{1 *}$, Loes Meeussen ${ }^{1}$, Karine Verschueren $^{1}$ and Karen Phalet $^{1}$

${ }^{1}$ University of Leuven, Belgium

Word count (exc. figures/tables): 6950

${ }^{*}$ Requests for reprints should be addressed to Laura Celeste, Center for Social and Cultural Psychology, Tiensestraat 102- bus 3727, 3000, Leuven, Belgium (e-mail:

laura.celeste@ppw.kuleuven.be).

Funding: Children of Immigrants Longitudinal Study (CILS) data collection was funded by the NORFACE Migration Research Program and, for Belgium, by the Leuven University

Research Council and by Flanders' National Science Foundation. 


\section{Minority acculturation and peer rejection: \\ Costs of acculturation misfit with peer group norms}

\section{Abstract}

How do minority adolescents' personal acculturation preferences and peer norms of acculturation affect their social inclusion in school? Turkish- and Moroccan-minority adolescents ( $\mathrm{N}=681$ ) reported their preferences for heritage culture maintenance, mainstream culture adoption, and their experiences of peer rejection as a key indicator of adjustment problems. Additionally, we aggregated peer acculturation norms of maintenance and adoption within ethnically diverse classrooms ( $\mathrm{N}=230$ in 50 Belgian schools), distinguishing between co-ethnic (Turkish or Moroccan classmates only $\mathrm{N}=681$ ) and crossethnic norms (also including N=1930 other classmates). Cross-ethnic peer group norms (of adoption and maintenance) and co-ethnic norms (of maintenance, marginally) predicted minority experiences of peer rejection (controlling for ethnic composition). Moreover, misfit of minorities' own acculturation preferences with both cross-ethnic and co-ethnic peer group norms was harmful. When cross-ethnic norms stressed adoption, 'integrationist' minority youth - who combined culture adoption with maintenance - experienced most peer rejection. Yet, when co-ethnic peers stressed maintenance, 'assimilationist' minority youth experienced most rejection. In conclusion, acculturation misfit with peer group norms is a risk factor for minority inclusion in ethnically diverse environments.

Keywords: ethnic diversity; acculturation; peer norms; integration; peer rejection 


\section{ACCULTURATION IN THE CLASSROOM}

\section{Minority acculturation and peer rejection: \\ Costs of acculturation misfit with peer group norms}

Ethnic diversity increases in younger generations, but we have yet to understand the social dynamics of the 'super-diverse' environments it creates (Vertovec, 2007). Today's minority youth is interacting on a daily basis with peers from many different cultural backgrounds, who share the same highly ethnically diverse neighborhoods, schools, or work settings (Hewstone, 2015). In spite of much evidence of the psychological benefits of diversity (Mok, Morris, Benet-Martínez, \& Karakitapoglu-Aygun, 2007), highly diverse environments also expose minority youth to heightened risks of experiencing social exclusion and discrimination (Baysu, Phalet, \& Brown, 2013; Rutland \& Killen, 2015). Thus, problems of some minority adolescents to 'fit in' with their ethnically diverse peer groups may trigger peer rejection, with long-term consequences for their future development. Zooming in on increasingly common yet under-researched high-diversity environments, we investigate peer rejection as a key indicator of social exclusion experiences among minority youth.

As minority adolescents explore their heritage culture, learn to navigate a common mainstream culture, and manage intercultural relations, socialization contexts outside the family become more influential, in particular the school context (Umaña-Taylor et al., 2014). Our study focuses on ethnically diverse classrooms in high school as proximal acculturation contexts. Schools constitute an important immediate social environment of minority adolescents where they encounter cultural differences and negotiate social inclusion in their daily interactions with peers. Peer groups are crucial normative contexts of social adjustment in adolescents (Rubin, Bukowski, \& Parker, 2006). Yet, little is known about the role of peer group norms in the acculturation and adjustment of minority youth (Verkuyten, 


\section{ACCULTURATION IN THE CLASSROOM}

Thijs, \& Sierksma, 2014). Peer norms of acculturation are defined here in accordance with a bi-dimensional approach of acculturation (Arends-Tóth \& Van de Vijver, 2006; Sam \& Berry, 2010): 'adoption' ${ }^{1}$ norms of acculturation promote minority engagement with the mainstream culture, while 'maintenance' norms stress the importance of preserving the heritage culture. Since acculturation attitudes are domain-specific (Arends-Tóth \& Van de Vijver, 2003) acculturation norms refer specifically to adoption and maintenance in the school context. Our study has a double aim. Focusing on minority experiences of peer rejection as outcomes, we will first test the role of cross-ethnic peer group norms of acculturation (including all peers in each class) and cross-ethnic misfit of minorities' own preferences. Next, we will examine the role of co-ethnic peer group norms (including only Turkish or Moroccan minority peers in each class) and misfit with a subgroup of co-ethnic peers in class.

To this end, we draw on large-scale surveys of Turkish and Moroccan Muslim minority youth and their classmates in highly ethnically diverse secondary schools in Flanders-Belgium. The children of Turkish and Moroccan immigrant workers are facing pervasive prejudice and discrimination as major Muslim minorities in European societies (Voas \& Fleischmann, 2012). Their school careers are marked by persistent socio-economic disadvantage and segregation into educational tracks and schools with relatively poor prospects in the labor market (Heath, Rothon, \& Kilpi, 2008). While their cultural and religious heritage is a prime source of self-worth and social support for most Turkish and Moroccan minorities, it is generally devalued in European mainstream cultures and societies (Güngör, Fleischmann, Phalet, \& Maliepaard, 2013).

Focusing on Turkish and Moroccan minority youth, our study adds to the state of the art in acculturation research by examining peer group norms within ethnically diverse 


\section{ACCULTURATION IN THE CLASSROOM}

classrooms as a most immediate and influential acculturation context. It is also the first to simultaneously study the role of normative forces in the cross-ethnic peer group of all classmates and in the co-ethnic subgroup of same-ethnicity peers in class. Furthermore, the study adds to the social-developmental literature on peer norms and peer rejection by focusing on acculturation norms as a crucial domain for the adjustment of minority youth. Finally, the study contributes to the social psychology of group norms in super-diverse multigroup contexts: it articulates simultaneous and selective normative influences on minorities as members of (co-ethnic) subgroups and (cross-ethnic) superordinate groups.

\section{Peer rejection as acculturation outcome}

To assess possible adjustment costs of acculturation misfit for minority youths, we focus on experiences of peer rejection as a key indicator of social exclusion. We define peer rejection broadly as the experience of active rejection or social avoidance by peers (Killen, Mulvey, \& Hitti, 2013; Rubin et al., 2006). When moving into adolescence, children become increasingly concerned about their position in peer groups (Rubin et al., 2006). Peer rejection is an important developmental risk factor in adolescence, predicting a range of adjustment problems including psychological maladjustment, depression, school avoidance, withdrawal, a lack of motivation, and poor achievement, both concurrently and longitudinally (Platt, Kadosh, \& Lau, 2013; Wentzel, 2009). Within the developmental literature, peer rejection/exclusion has often been attributed to interpersonal or individual characteristics, however this neglects the important role of group processes (Rutland \& Killen, 2015). Children and adolescents are sensitive to group norms (Abrams \& Rutland, 2008; Killen, Rutland, Abrams, Mulvey \& Hitti, 2013), and use these norms as guidelines to express prejudice or socially exclude peers (Nesdale, Maas, Durkin, \& Griffiths, 2005;

Rutland, Cameron, Milne, \& McGeorge, 2005; Rutland \& Killen, 2015). In ethnically diverse 


\section{ACCULTURATION IN THE CLASSROOM}

classrooms therefore, both minority and majority youth will be aware of prevailing classroom norms, and may reject minority peers who deviate from these norms. Likewise, minority youngsters may exclude their minority peers who do not fit with co-ethnic subgroup norms within their classroom. Specifically, we aim to examine acculturation norms as a relevant aspect of group dynamics within diverse classrooms which can help us understand minorities' experiences of peer rejection. Peer rejection as a relational outcome will give insight into the overall quality of minority adolescents' social relationships in relation to acculturation issues.

\section{Acculturation Norms and Preferences}

Developmental research has amply documented the role of peer norms, and specifically of peer norms operating in classrooms, in shaping adolescents' adjustment outcomes (Kindermann, 2007; Wentzel, 2009). While the norms that are most frequently studied refer to school-related attitudes and behaviors, the present study extends this research by focusing on acculturation norms in class. At the individual level, maintenance and adoption orientations form four possible acculturation preferences: integration, assimilation, separation, and marginalization (Sam \& Berry, 2010); integration values both heritage culture maintenance and mainstream culture adoption; assimilation values mostly adoption; separation mostly maintenance; and marginalization ${ }^{2}$ neither.

Findings on minorities' own acculturation preferences are mixed, documenting the adjustment benefits of both adoption and maintenance orientations (Ward \& Kennedy, 1994). In particular, integration (i.e. a combination of high maintenance with high adoption) has been related to benefits (peer acceptance and social competence) as well as costs (such as maladaptive emotional symptoms) for minority adjustment (Brown et al., 2013). Another study finds that longitudinally integrationists perceive greater peer acceptance over time 


\section{ACCULTURATION IN THE CLASSROOM}

(Rutland et al., 2012). However, we also know that minorities' own acculturation and adjustment are influenced by the views of others in their social environment and need to be understood within the social context. For instance, integration can be psychologically demanding for minorities in the absence of social support from significant others. Research into others' views on acculturation mainly studies (perceived or manipulated) views of the majority group in the larger society (Brown \& Zagefka, 2011). This research shows the expected negative consequences of acculturation misfit, for instance when minority members prefer integration or separation while the majority group favors assimilation (Bourhis, Moïse, Perreault, \& Senécal, 1997; Piontkowski, Rohmann, \& Florack, 2002). Extending previous studies of acculturation misfit, we reason that acculturation (mis)fit of minorities' own acculturation preferences with their immediate social environment will be most consequential for social inclusion.

Existing acculturation research mainly focuses on the views of the societal majority group. In highly diverse social environments, however, the nominal majority group no longer makes a numerically dominant group that defines acculturation norms. In the super-diverse environment of today's schools in Europe, therefore, different cultural groups can contribute to peer group norms; and minority groups can be highly influential. Along those lines, adolescents' cultural socialization is shaped by their co-ethnic peer relations within minority groups as well as cross-ethnic relations with all peers in their class across different minority and majority backgrounds (Kiang, Harter, \& Whitesell, 2007). In support of this distinction, developmental research explains that different normative processes underlie peer evaluations within one's in-group and between groups (Abrams, Rutland, \& Cameron, 2003; Killen, Rutland, et al., 2013). For our purposes, we define cross-ethnic acculturation norms at the superordinate level of the classroom as a common in-group which minority youth share 


\section{ACCULTURATION IN THE CLASSROOM}

with all peers in class. In parallel, we define co-ethnic acculturation norms at the subgroup level including only peers in class with similar Turkish or Moroccan minority backgrounds. Minorities' co-ethnic peers are embedded as distinct ethnic subgroups within ethnically diverse classrooms as superordinate groups (Hornsey \& Hogg, 1999). Minorities' double classroom and ethnic group membership implies that both cross-ethnic and co-ethnic peer groups take on psychological significance as normative contexts of acculturation.

\section{Cross-ethnic peer norms and acculturation misfit}

Diverse classrooms are a psychologically relevant proximal acculturation context, because minority youth share with classmates from different cultural backgrounds not only daily interactions and activities, but also their common or superordinate membership as students of the same school and class. Our first aim is to examine the impact of cross-ethnic peer norms of acculturation in the Belgian school context, including all peers in the classroom. In contemporary European societies, Muslim minorities in particular face assimilationist pressures to adopt the mainstream culture (Guimond, de la Sablonnière, \& Nugier, 2014; Phalet, Baysu, \& Van Acker, 2014). Thus, majority members in Belgium - as in other European societies - commonly expect Muslim minorities to adopt mainstream customs and values, which they see as incompatible with Islamic heritage cultures (Phalet \& Kosic, 2006; Van Acker \& Vanbeselaere, 2012). On the other hand, Muslim minorities in particular tend to value culture maintenance, most often preferring integration or even separation over assimilation into mainstream European cultures (Berry, Phinney, Sam, \& Vedder, 2006; Güngör et al., 2013). With distinct majority and minority perspectives on acculturation in a European migration context, this raises the question how minority youth who prefer to maintain the heritage culture fare in a social environment which stresses adoption of the mainstream culture. Against the backdrop of societal assimilationism, we 


\section{ACCULTURATION IN THE CLASSROOM}

aim to test possible adjustment costs of acculturation misfit of minority maintenance with prevailing adoption norms. In support of the costs of acculturation misfit, there is evidence that the misfit of assimilationist majority views with minority preferences for integration predicts negative intergroup relations (Brown \& Zagefka, 2011 for a review). Additional indirect support comes from recent evidence of a downside of integration preferences for minority adjustment in less welcoming school contexts (in the UK: Brown et al., 2013; and in Belgium: Baysu, Phalet, \& Brown, 2011). We hypothesize that strong cross-ethnic peer norms of adoption - when seen as opposing maintenance in an assimilationist societal climate - will predict rejection experiences for minority youth who strive to maintain the heritage culture or to integrate both cultures (Hypothesis 1; two-way or three-way interaction effects of cross-ethnic adoption norms with minority maintenance or with the interaction of minority maintenance and adoption).

\section{Co-ethnic peer norms and acculturation misfit}

Most acculturation research studies intergroup relations rather than social relations within minority groups, yet co-ethnic peers are a psychologically meaningful and important reference group (Verkuyten \& Martinovic, 2012). Our second aim is to examine the impact of co-ethnic peer norms of acculturation, focusing on the co-ethnic subgroup of Turkish or Moroccan minority peers in each class. In spite of their devalued minority position in European societies, in many schools Turkish and Moroccan minorities are a numerous and socially influential group. For minority youth their co-ethnic peers in class are a psychologically significant in-group. When minorities identify with their group, or when their minority identity is situationally salient, they are motivated to align their attitudes with group norms (Haslam, Powell, \& Turner, 2000). Accordingly, minorities make interpersonal comparisons predominantly within their ethnic group rather than intergroup comparisons with 


\section{ACCULTURATION IN THE CLASSROOM}

the majority (Smith \& Leach, 2004). Also, deviance from (or misfit with) co-ethnic peer norms can be detrimental for minorities' well-being (Sassenberg, Matchke, \& Scholl, 2011). Thus, being perceived as too mainstream by co-ethnic group members negatively affected the acculturative adjustment of South-Asian minorities in Canada (Abouguendia \& Noels, 2001).

Being highly identified as Muslims and facing widespread public hostility against Muslims in Europe (Güngör et al., 2013; Verkuyten \& Yildiz, 2007), we reason that Muslim minority youth will be especially receptive to normative pressures from co-ethnic peers in class. Along those lines, perceived co-ethnic norms to maintain the heritage culture were found to predict more commitment of Turkish-Dutch Muslim minorities to their cultural identity (Martinovic \& Verkuyten, 2011). Moreover, we know that most Turkish and Moroccan minorities across Europe are strongly committed to their ethnic and religious minority identity (Fleischmann \& Phalet, 2015) and wish to preserve their heritage culture (Berry et al., 2006; Güngör et al., 2013). This raises the question how minority youngsters fare when they strive to adopt the mainstream culture and their co-ethnic peers stress culture maintenance - in line with generally high ethnic retention in Muslim communities. To our knowledge, no research addresses the costs of acculturation misfit with co-ethnic peer norms. We reason that co-ethnic maintenance norms may be detrimental for minority adolescents who strive to adopt the mainstream culture or who prefer to combine mainstream and heritage cultures. Specifically, we hypothesize more frequent rejection experiences in the presence of strong co-ethnic peer norms of maintenance for minority youth who strive to adopt or to integrate (Hypothesis 2; two-way or three-way interaction effects of co-ethnic maintenance norms with minority adoption or with the interaction of minority maintenance and adoption).

Finally, seeing that relative minority group size can impact minority school 


\section{ACCULTURATION IN THE CLASSROOM}

adjustment (Baysu et al., 2013) we also explore the role of ethnic composition (measured as percentages of Turkish or Moroccan co-ethnic peers in class). This allows us to test if ethnic composition explains away (part of) minorities' experiences of peer rejection. We test whether the hypothesized normative impact of cross-ethnic and co-ethnic peer groups holds across classrooms where Turkish and Moroccan minorities are more or less numerous (i.e., main and interaction effects of the proportion of Turkish and Moroccan minorities in class).

\section{Method}

\section{Procedure}

Large-scale survey data were collected in ethnically diverse classrooms in randomly sampled secondary schools in Flanders-Belgium (Children of Immigrants Longitudinal Study Flanders, 2014). The Belgian study design and measures were modelled on the international CILS4EU research (Kalter et al., 2014). Detailed information regarding the complete Belgian samples, constructs and measures can be found in the technical report (Emonds, Meeus, Heikamp, \& Meulemans, 2014). After obtaining informed consent from school principals and teachers, participants and their parents were given the opportunity to opt out preceding our school visit and again at the start of each session. Participants completed two Dutchlanguage paper-and-pencil questionnaires in class with the assistance of trained research assistants and in the presence of a teacher. Experiences of peer rejection (part 1) were measured before any mention of cultural background or acculturation (part 2).

\section{Participants}

We use data from $N=2611$ participants (Turkish and Moroccan minorities and their classmates), within 203 classrooms in 50 Flemish high schools. ${ }^{3}$ We investigate predictors of Turkish and Moroccan minority pupils' experience of peer rejection (i.e. our dependent variable includes only the minority subsample). 


\section{ACCULTURATION IN THE CLASSROOM}

Using self-reported own country of birth and parentage (i.e., one or both foreignborn parents or grandparents) we selected Turkish and Moroccan immigrant origin adolescents as our ethnic minority sample $(N=681 ; 48.6 \%$ male, 19 unspecified; Age $M=$ $15.09, S D=1.22)$; most were $2^{\text {nd }}$ generation $\left(1^{\text {st }} N=91 ; 2^{\text {nd }} N=559,3^{\text {rd }} N=31\right) ; 52 \%$ were of Turkish origin; and $37 \%$ attended vocational tracks. Turkish and Moroccan minority youth were strongly committed to their distinct Muslim identity (93\% self-identified as Muslim of which $99 \%$ reported that religion was important to them).

Cross-ethnic peer norms were aggregated over all classmates $(N=2611)$, including both minority and majority Belgian peers $(N=843)$ (i.e., $4^{\text {th }}$ generation plus of local-born parentage). In addition to Turkish and Moroccan minorities $(N=681$; Turkish $N=352$; Moroccan $N=329$ ), other minority groups came from many different and generally less stigmatized cultural backgrounds $(N=1087)$. Cross-ethnic peers came from 89 different countries of origin across classrooms ${ }^{4}$, though most had a European background (the Netherlands $N=108$; Poland $N=55$; Bulgaria $N=23$; Spain $N=21$, Albania $N=21$, all other countries $N \leq 21$ ). This implied that - with the exception of major Turkish and Moroccan subgroups - numbers of co-ethnic peers were too small for separate analyses of the many different cultural subgroups at the classroom level. Reflecting the ethnic stratification and segregation of secondary education in Belgium (Baysu et al., 2013), also majority Belgian peers were a numerical minority in most classes of our Turkish and Moroccan minority participants. They made up $22.5 \%(S D=.21)$ of the classrooms on average; $90 \%$ of our sample were in majority minority classes ( $<50 \%$ majority peers); $23 \%$ had no majority classmates at all. As majority peers formed a significant cultural subgroup in some classes of Turkish and Moroccan minority participants and not in others, they could not be analyzed separately at the classroom level. 


\section{ACCULTURATION IN THE CLASSROOM}

\section{Measures}

Own acculturation preferences. To assess acculturation preferences, we used singleitem measures for the two acculturation dimensions of culture maintenance and adoption separately (Arends-Tóth \& Van de Vijver, 2006). Their statistical interaction (i.e., product term of maintenance and adoption) indicated minorities' preference for integration (high adoption at high maintenance; cf. supra). As acculturation preferences are domain-specific, we measured both orientations in the school context (Arends-Tóth \& Van de Vijver, 2003). Specifically, Turkish and Moroccan minority participants were asked, regarding their heritage culture, "how important is it for you to maintain the customs of this country at your school" and "... to adopt the Belgian customs at your school". Answers were scored on a four-point Likert scale from (1) not important to (4) very important. These items were replicated from the international TIES surveys (cf. Güngör, Fleischmann, \& Phalet, 2011). In line with earlier findings in (young) adults, Turkish and Moroccan minorities rated both culture maintenance and adoption as rather important in the school context $(M=2.52, S D=1.03 ; M=2.82, S D=$ 0.96). A weak yet significant positive correlation of maintenance with adoption $(r=.16, p<$ .001 ) showed that minorities saw heritage and mainstream cultures as compatible rather than conflicting.

Peer acculturation norms. We asked Turkish and Moroccan minority participants as well as all other classmates about their acculturation norms, with separate single-item measures for culture maintenance and adoption. As distinct from acculturation preference measures (cf. supra), our measures of acculturation norms assessed what participants thought minorities should be doing. All participants rated the following statements, replicated from the international CILS4EU surveys (Kalter et al., 2014): “Migrants should do everything possible to preserve the customs of their country" (maintenance) and "Migrants 


\section{ACCULTURATION IN THE CLASSROOM}

should adopt the Belgian customs in this country" (adoption). Items were scored on a fivepoint Likert scale, (1) strongly disagree to (5) strongly agree.

Peer group norms of maintenance and adoption were calculated separately as the average maintenance and adoption scores of participants' classmates. More precisely, crossethnic norms were aggregated over all peers in each class, while co-ethnic norms were aggregated over Turkish and Moroccan minority peers in class only. Averages were calculated excluding the individual scores of Turkish and Moroccan minority participants. For each participant four unique individual-level scores were calculated for cross-ethnic and coethnic peer norms of maintenance and adoption respectively. We partialled out individual scores to avoid confounding personal preferences with normative conformity. In this way, we sought to spell out the interplay of minorities' own acculturation preferences with peer group norms as external or contextual normative forces proper.

Our measure of cross-ethnic peer norms was in line with Chang's (2004) operationalization of classroom norms as a class average. As classroom norms need not be consensual in order to influence behavior, (partial) averages are a valid indicator of peer norms in class (Chang, 2004). Extending the same logic to co-ethnic peer norms, we also averaged Turkish and Moroccan peers' responses within each classroom for maintenance and adoption separately. To estimate the contextual effects of the co-ethnic peer group, norms were again calculated net of one's own preferences.

Mean cross-ethnic peer norms were above the scale midpoint (neither agree nor disagree) for both maintenance and adoption in school $(M=3.17, S D=0.52 ; M=3.38, S D=$ $0.51)$ and significantly negatively correlated $(r=-.22, p<.001)$, in line with prevailing assimilationist views of culture maintenance as conflicting with adoption in Belgian society at large. Mean co-ethnic peer norms for maintenance and adoption were around the scale 


\section{ACCULTURATION IN THE CLASSROOM}

midpoint $(M=3.49, S D=0.67 ; M=2.95, S D=0.80)$, yet they were positively correlated $(r=$ $.17, p<.001)$, suggesting that co-ethnic minority peers saw the different cultures as compatible rather than conflicting.

Peer rejection. To assess minority experiences of peer rejection, six items were taken from the 'exclusion/rejection' dimension of the PEDQ-CV scale (Brondolo et al., 2005) and adjusted to fit the school setting. The items covered both victimization/aggression and exclusion/avoidance components of peer rejection. They formed a reliable scale $(\alpha=.91)$ asking: "How often do you experience that other pupils: bully you; treat you unfairly or in a hostile way; threaten or bother you; shut you out; let you know you are not really welcome; call you names or insult you." Items were scored on a four-point scale from (1) never to (4) always. Close to half (45.8\%) of our Turkish and Moroccan minority participants indicated that they experienced peer rejection sometimes (2) or often (3). As usual, mean selfreported levels of rejection were quite low $(M=1.34, S D=0.57)$. Items asked about general peer rejection experiences, including both rejection from within minority groups and between the different minority and majority subgroups in class.

Control variables. Since our explanatory focus is on normative processes in multigroup environments, we controlled for possibly influential individual differences. We measured age, gender $(0=$ male), and school track (vocational $=0$; academic, technical, or art-based $=1$ ). Self-reported Dutch-language grades and grade retention (whether or not participants ever repeated a grade) were not significant predictors of peer rejection ( $p s>$ .25), so were removed from the models. As a contextual measure of school segregation, we used administrative data on the ethnic composition of Belgian schools, which indicated the presence of youngsters speaking a foreign language at home $(0-10 \%=1 ; 10 \%-30 \%=2 ; 30 \%-$ $60 \%=3$ ). To explore the effects of the relative group size of Turkish and Moroccan 


\section{ACCULTURATION IN THE CLASSROOM}

minorities in class as a possible predictor or moderator of (normative effects on) peer rejection, we calculated the percentage of Turkish and Moroccan minorities for each class ( $N$ Turkish and Moroccan minority participants $/ N$ all classmates) as a continuous variable $(M=$ $41 \%, S D=0.22$.

\section{Results}

\section{Acculturation preferences and peer rejection}

Means, standard deviations, and correlations are reported in Appendix 1. To account for the nested structure of our data, we first conducted a three-level analysis (participants at level 1 , classrooms at level 2, schools at level 3) of peer rejection with a random intercept and without predictors (Hox, 2010). This model showed no significant variance in peer rejection at either the school level $\left(\sigma_{\mathrm{v} 0}{ }^{2}=.003, p=.66\right.$; VPC $\left.=.01\right)$ or the class level $\left(\sigma_{\mathrm{u} 0}{ }^{2}=\right.$ $.02, p=.15 ; \mathrm{VPC}=.08)$, not necessitating multilevel analysis. ${ }^{5}$ To investigate our hypotheses therefore, we used individual-level regression models in Mplus, version 7 (Muthén \& Muthén, 1998-2012). All continuous predictors were grand-mean centered (Hox, 2010). Models included age, gender, school track, and percentage of all minorities in school as control variables. In addition, we included the percentage of Turkish and Moroccan minorities in class as a possible moderator of peer group norms. While we did not propose specific hypotheses about classroom composition, moderation analyses tested the generalizability of normative effects across classes with different relative group sizes of Turkish and Moroccan minority youth. Given the skewness of our peer rejection variable (skew $=2.48)$, we used robust MLR maximum likelihood estimation with robust standard errors against non-normality (Muthén \& Muthén, 1998-2012).

We conducted step-wise models to test the improvement of each model starting with the null model (Deviance $-2 \mathrm{LL}=975.87 ; \mathrm{AIC}=979.87 ; \mathrm{BIC}=988.65)$. Robust Satorra- 


\section{ACCULTURATION IN THE CLASSROOM}

Bentler scaled chi-square difference tests $\left(\Delta \chi^{2}\right)$ showed that model fit improved significantly in each step. In a second step the model included covariates only (Deviance -2LL= 874.58; $\left.A I C=888.58 ; B I C=918.60 ; \Delta \chi^{2}(5)=94.81, p<.001\right) . A$ third step added the effects of minority's own acculturation preferences (maintenance, adoption, and their interaction: integration) and the moderation (interaction) of these acculturation effects by the percentage of Turkish and Moroccan minority youth in class, (Deviance $-2 \mathrm{LL}=683.39 ; \mathrm{AIC}=$ 709.39; $\left.\mathrm{BIC}=763.37 ; \Delta \chi^{2}(6)=188.23, p<.001\right)$. This model showed no significant effects of own acculturation preferences on peer rejection ( $p s>.244)$ and no significant moderation by the percentage of Turkish and Moroccan minority youth in class $(p s>.10) .{ }^{6}$

To test our hypotheses, we estimated two separate final models, adding in a fourth step peer acculturation norms (maintenance and adoption) and the statistical interactions of minorities' own preferences (indicated by maintenance, adoption, and their interaction: integration) with peer norms of maintenance or adoption. The models also tested moderation effects of the percentage of Turkish and Moroccan minority youth in class (interactions with all acculturation measures). One final model tested cross-ethnic norms as peer norms, while the other final model tested co-ethnic norms. Parameter estimates and standard errors for our final two models are reported in Table 1, labeled Model 1 (crossethnic peer norms) and Model 2 (co-ethnic peer norms). Importantly, the final models showed significant model fit improvement from the third step for cross-ethnic norms (Model 1) and co-ethnic norms (Model 2), respectively $\Delta \chi^{2}(16)=40.56, p<.001, \Delta \chi^{2}(16)=116.08, p$ $<.001$. We now report the results from our final models which tested our hypotheses, starting with results for cross-ethnic norms (Hypothesis 1) followed by co-ethnic norms (Hypothesis 2). 


\section{ACCULTURATION IN THE CLASSROOM}

\section{Cross-ethnic acculturation norms and peer rejection.}

We expected that cross-ethnic adoption norms would predict minority experiences of peer rejection for minorities who prefer to maintain or to integrate (Hypothesis 1 ). As can be seen in Table 1 (Model 1), controlling for individual level predictors of peer rejection, we found a significant main effect of cross-ethnic peer adoption norms ( $B=0.16, p=.031$ ), so that strong cross-ethnic adoption norms predicted greater minority experience of rejection. As expected, this effect of adoption norms was qualified by significant higher-order interactions with minorities' own acculturation preferences (cf. infra). In addition, we also found an unexpected significant main effect for cross-ethnic maintenance norms $(B=0.14, p$ $=.039$ ). There were no significant interactions of maintenance norms with minorities' own acculturation preferences, however. We will discuss the role of maintenance norms in light of our findings on co-ethnic peers in class in the discussion section.

In line with Hypothesis 1 about acculturation misfit, a significant three-way interaction of minorities' own integration preference (maintenance*adoption) and crossethnic adoption norms emerged $(B=0.34, p=.037)$. Figure 1 shows that preference for integration predicted the most rejection in the presence of a strong cross-ethnic adoption norm. Supporting Hypothesis 1, a misfit between cross-ethnic norms stressing adoption and minorities' preference to integrate both cultures (perceived to be conflicting by cross-ethnic peers) predicted greater rejection.

\section{[Insert Figure 1 about here]}

With a view to interpreting this interaction effect, Wald Chi-Square tests indicated significant simple slopes (Muthen \& Muthen, 1998-2012). Comparing classrooms with weak (-1SD) vs. strong (+1SD) cross-ethnic adoption norms, only minorities who preferred integration (high (+1SD) maintenance and high (+1SD) adoption) were significantly worse off 


\section{ACCULTURATION IN THE CLASSROOM}

when cross-ethnic peers stressed adoption more (Wald $\left.\chi^{2}(1)=7.57, p=.006\right)$. Furthermore, comparing minorities with different acculturation preferences within classes with strong adoption norms, integrationists experienced significantly more rejection compared to only those endorsing assimilation (Wald $\chi^{2}(1)=3.80, p=.051$ ) but did not differ significantly from those who preferred separation. In contrast, comparing between acculturation preferences in classes with a weak adoption norm, integrationists experienced significantly less rejection than those who preferred either assimilation (Wald $\chi^{2}(1)=3.79, p=.052$ ) or separation (Wald $\left.\chi^{2}(1)=4.28, p=.039\right)$.

In line with the hypothesized cost of acculturation misfit with cross-ethnic peers for minority inclusion, integrationists and separationists were similarly rejected in the presence of a strong adoption norm, yet only integrationist, not separationist minorities were protected from experiencing rejection in the absence of a strong norm. Assimilationists fared better than integrationist minorities only in classes with a strong adoption norm, but they were more at risk than integrationists in the absence of a strong norm.

The effects of cross-ethnic peer norms on minority experiences of peer rejection largely generalized across classes with a different ethnic composition except for one significant interaction $(B=0.63, p=.044)$ : in classes with more Turkish and Moroccan minority youth, cross-ethnic adoption norms predicted peer rejection more strongly.

\section{Co-ethnic acculturation norms and peer rejection}

In order to test Hypothesis 2, we re-tested our final model, using co-ethnic acculturation norms as the peer norms to predict minority experiences of peer rejection (Table 1, Model 2). Controlling for individual-level predictors of peer rejection, the main effect of co-ethnic peer norms of maintenance neared significance $(B=0.08, p=.07)$. This near significant effect suggests a tendency towards greater peer rejection in classes with 


\section{ACCULTURATION IN THE CLASSROOM}

stronger co-ethnic maintenance norms. As expected, this tendency was qualified by a significant interaction with minorities' own acculturation preferences. There were no significant effects of co-ethnic adoption norms. Percentage of Turkish and Moroccan minorities in class significantly predicted rejection $(B=0.35, p=.042)$, showing greater rejection experiences in classes with more Turkish or Moroccan minority youth. Again, higher-order interactions with acculturation norms and preferences qualified this effect.

We expected a misfit effect so that co-ethnic maintenance norms would affect minorities who preferred to adopt the mainstream culture or to integrate the cultures (Hypothesis 2). Along those lines, a significant two-way interaction between co-ethnic maintenance norms and minorities' own preferences for adoption emerged $(B=0.09, p=$ .016): in the presence of a strong co-ethnic peer norm of maintenance, minorities who wanted to adopt the mainstream culture reported greater rejection, supporting Hypothesis

2. The three-way interaction of own integration preference (maintenance*adoption) and coethnic maintenance norms was not significant $(B=0.01, p=.75)$, however. To visualize the impact of co-ethnic maintenance norms (Hypothesis 2), Figure 2 depicts minority acculturation preferences as a function of co-ethnic maintenance norms.

\section{[Insert Figure 2 about here]}

Comparing classrooms with weak (-1SD) vs. strong (+1SD) co-ethnic maintenance norms, Wald Chi-square tests revealed a significant slope only for assimilationist minorities (low maintenance and high adoption) (Wald $\left.\chi^{2}(1)=4.85, p=.028\right)$ : they experienced more rejection in classes with stronger co-ethnic maintenance norms as compared to weak norms (see Figure 2). There were no significant differences between minorities with different acculturation preferences in classrooms with strong co-ethnic maintenance norms. In classes with a weak maintenance norm, however, both assimilationist (Wald $\chi^{2}(1)=4.68, p=.031$ ) 


\section{ACCULTURATION IN THE CLASSROOM}

and integrationist minorities (Wald $\chi^{2}(1)=4.39, p=.036$ ) experienced significantly less rejection than those endorsing separation.

In line with the hypothesized cost of acculturation misfit with co-ethnic peers for minority inclusion, assimilation preferences increased rejection risks in the presence of a strong maintenance norm. Separationist minorities were more often rejected than others only in classes with weak maintenance norms, while integrationists fared relatively well regardless of the maintenance norm.

Finally, co-ethnic peer effects largely generalized across classes with a different ethnic composition, except for one significant interaction effect. Co-ethnic adoption norms moderated the interaction of percentage of Turkish and Moroccan minorities in class with minority preference of integration $(B=-0.29, p=.022)$ : only when minorities preferred integration and co-ethnic peers stressed adoption, the association of relative minority group size with more peer rejection was attenuated. Apparently, the same minority presence in class provoked less rejection when minorities endorsed mainstream culture adoption.

\section{Discussion}

Today's minority youth are often growing up in highly ethnically diverse social environments in which many different ethnic groups contribute to the prevailing acculturation norms. To understand how diverse contexts shape the acculturation experiences of minority youth, we examined the nature and consequences of peer norms of acculturation and the costs of acculturation misfit with minorities' own acculturation preferences. To this end, we examined perspectives from Turkish and Moroccan Muslim minorities as most disadvantaged and devalued immigrant populations in Flanders-Belgium, a European migration context of predominant assimilationism. Our research context and groups extend beyond studies conducted in acculturation contexts which promote pluralism, 


\section{ACCULTURATION IN THE CLASSROOM}

often finding benefits of minority integration (Bourhis, Barrette, El-Geledi, \& Schmidt, 2009).

Our study demonstrates the key role of peer acculturation norms in ethnically diverse classrooms as proximal acculturation contexts for minority adolescents. Our findings reveal that acculturation issues play a key role in explaining their experiences of social exclusion.

In essence, we find that it can be detrimental for minorities to deviate (misfit) from both cross-ethnic peer norms in their class groups and co-ethnic peer norms in their minority subgroups. Misfit in the presence of a strong cross-ethnic peer adoption norm was the most costly for minority youth preferring to integrate (Hypothesis 1). Conversely, misfit with coethnic peer norms of maintenance predicted most peer rejection when minority youth preferred to assimilate to the mainstream culture (Hypothesis 2). In addition, a detrimental effect of greater minority presence in class (significant in the co-ethnic model only) may be due to perceived threat (Van Acker \& Vanbeselaere, 2012) as the effect vanished when minorities endorsed adoption (as evident from a significant interaction of numbers, norms and preferences). Finally, an unexpected negative effect of cross-ethnic maintenance norms may reflect the contribution of minorities to the classroom norm such that minorities are more concerned with culture maintenance (Berry et al., 2006) as reflected in our co-ethnic misfit effect.

The findings add to existing research on social exclusion and acculturation in several ways. We build on the general developmental finding that peer groups form crucial normative contexts for adolescents (Rubin et al., 2006) with long-term consequences for their adjustment (Wentzel, 2009). Extending this research to ethnically diverse contexts of adolescent development, we focus on acculturation as a key issue in minorities' peer relations. Accordingly, the normative misfit of their own preferences with peer group norms predicted social exclusion. Bridging developmental research with acculturation and 


\section{ACCULTURATION IN THE CLASSROOM}

intergroup relations, we focus on group dynamics rather than (inter)personal factors

(Abrams \& Rutland, 2008). Thus, we related social exclusion to distinct normative effects from two peer groups of minority youth: the common class group of cross-ethnic peers and the minority subgroup of co-ethnic peers.

The findings also shed new light on previous mixed evidence in the field of acculturation studies, which indicated both benefits and costs of integration for minorities (Brown et al. 2013, Rutland et al., 2012). We find that integration can be either helpful or harmful for minority adolescents depending on the normative context of acculturation. In line with an interactive approach of acculturation (Brown \& Zagefka, 2011), our study shows that we need to consider the interplay of minorities' own preferences with the acculturation norms of their peer groups. Furthermore, our research refines the notion of acculturation norms by examining both cross-ethnic peer norms and co-ethnic peer norms in highly diverse acculturation contexts. While rapid demographic changes along multiple dimensions of migration-related diversity, such as ethnicity, religion, language, and migration status, have created so-called 'super-diverse' social environments (Vertovec, 2007), these drastic changes have not received the attention they deserve in acculturation studies. As the reality of 'super-diversity' in Belgium is coupled with segregation, minorities' experiences of acculturation are shaped by their engagement in highly diverse 'majority-minority' environments. The present study is a modest attempt to better acknowledge the social world of these youngsters by asking who defines acculturation norms for them. Rather than assuming that the societal majority group defines the norm, we examined the cross-ethnic class group as a more inclusive, more proximal, and more internally diverse common group (Bourhis et al, 1997; Piontkowski et al, 2002). And we took into account less researched 


\section{ACCULTURATION IN THE CLASSROOM}

normative forces from within minority groups as well (Abouguendia \& Noels, 2001;

Sassenberg et al., 2011).

Interestingly, cross-ethnic and co-ethnic peer norms of acculturation affect the inclusion of minority youth in distinct ways. Superordinate (cross-ethnic) group norms reflect the wider Belgian societal climate which promotes adoption, where we see a detrimental misfit on adoption norms. In contrast, (co-ethnic) subgroup norms prioritize maintenance, where we see a detrimental misfit on maintenance norms. Cross-ethnic norms were more restrictive than co-ethnic norms. Specifically, cross-ethnics rejected integrationists as falling short of strong adoption norms, while separationists were rejected as deviant even at low adoption norms. Alternatively, co-ethnics were mostly concerned about assimilationist minorities whose preferences were in direct conflict with strong maintenance norms. This differential restrictiveness may reflect the unequal status/power between the groups, with low-status minority groups being less influential in society relative to the superordinate group who represents more closely the societal climate and hence has more normative power. At the same time, both types of peer norms matter in different ways for minority inclusion in highly diverse intergroup contexts. By implication, studying normative fit between minorities and different peer groups in their immediate social environment may be an important new avenue for acculturation research.

\section{Empirical Strengths and Limitations}

Our study has several empirical strengths. Thus, we assess misfit with actual acculturation norms as reported by classmates themselves (Chang, 2004), rather than with commonly studied self-perceived attitudes of others (Piontkowski et al., 2002). Moreover, we concentrate on the acculturation norms of peers rather than measuring general perceptions or attitudes in society. Such measures are less instructive for interventions, as 


\section{ACCULTURATION IN THE CLASSROOM}

country or societal-level changes are more difficult to pursue (Dixon, Durrheim, \& Tredoux, 2005). Instead, the classroom is a manageable social setting for implementing interventions. With the present study we aim to steer research towards more situated interventions designed to create inclusive social environments supportive of diversity. Our research suggests that norms within classrooms should be targeted in order to make a change. Teachers are in a pivotal position as leaders of their classrooms to create change through norm setting (Meeussen, Otten, \& Phalet, 2014). As a practical application of our findings, future research may intervene with teachers to influence cross-ethnic and co-ethnic peer norms alike.

Finally, assessing interpersonal rejection as an outcome measure also moves beyond general intergroup attitudes as acculturation outcomes. Minority adolescents are not generally more likely to be rejected than their peers (Durkin et al., 2012). Thus, it is notable that we find that peer rejection (i.e., not explicitly ethnic discrimination) is directly related to minority peers' acculturation norms, particularly while controlling for other individual characteristics. This suggests that interpersonal peer rejection (partly) reflects intergroup exclusion, depending on judgments or attitudes in the given intergroup context (Killen, Mulvey et al., 2013).

But there are also clear limitations. The correlational nature of our research is a limitation, as we cannot make claims about the causal direction between our variables. Although our reasoning is in line with previously found longitudinal effects of (prior) acculturation attitudes on measures of adaptation (Brown et al., 2013; Rutland et al., 2012), it is conceivable that repeated experiences of rejection could eventually lead minority youth to either separate or assimilate (depending on their commitment to co-ethnic and/or crossethnic peer groups). Yet, because we measure rejection in general (not from a specific 


\section{ACCULTURATION IN THE CLASSROOM}

group, and not discrimination) we would not expect general rejection from all peers to predict any specific change in acculturation preferences. Future research should take a longitudinal approach to acculturation norms to test causation. It would also be interesting to investigate whether minorities adjust their acculturation preferences to either crossethnic or co-ethnic peer norms over time. Furthermore, we do not yet know how the acculturation norms within a class are formed. Further research could investigate potential influences such as teachers and school policies, which may shape the normative climate among peers as well. This could help researchers implement contextually relevant school interventions.

While we did have a large and highly diverse sample, there was not a large enough within-class subgroup among the other minorities to assess their relative contributions to cross-ethnic norms. However, initial investigations suggest that the classroom cross-ethnic normative influence is neither clearly majority-Belgian majority nor minority. Further research could look more closely at the ties of influence within a classroom through social network analyses. Finally, our participants were Turkish and Moroccan minorities as most socially disadvantaged and discriminated groups in European societies (Güngör et al., 2013). Future research should test the generalizability of these results to less disadvantaged minority groups, and in equally diverse and more multiculturalist societal contexts.

\section{Conclusion}

Our research shows that misfit of minority acculturation preferences with peer group norms can jeopardize their social inclusion. Both cross-ethnic peer norms of adoption, which reflect common assimilationism in the wider society and co-ethnic peer norms of maintenance, which reinforce cultural attachments in minority communities, can be harmful when they misfit with minorities' acculturation preferences. Challenging the adaptive value 


\section{ACCULTURATION IN THE CLASSROOM}

of integration in some acculturation contexts (Brown \& Zagefka, 2011; Sam \& Berry, 2010), we find that this most preferred strategy for minorities (Brown, 2010) can be problematic when peers do not support integration. This suggests that in order to allow minority youth to integrate, interventions (potentially with teachers) targeting peer norms of acculturation can promote peer acceptance. 


\section{References}

Abouguendia, M., \& Noels, K.A. (2001). General and acculturation-related daily hassles and psychological adaptation in first and second-generation South Asian immigrants to Canada. International Journal of Psychology, 36, 163-173. DOI:

$10.1080 / 00207590042000137$

Abrams, D., \& Rutland, A. (2008). The development of subjective group dynamics. In S. Levy \& M. Killen (Eds.), Intergroup attitudes and relations in childhood through adulthood. Oxford, UK: Oxford University Press.

Abrams, D., Rutland, A., \& Cameron, L. (2003). The development of subjective group dynamics: Children's judgments of normative and deviant in-group and out-group individuals. Child Development, 74: 1840-1856. DOI: 10.1046/j.14678624.2003.00641.x

Arends-Tóth, J., \& Van de Vijver, F.J.R. (2003). Multiculturalism and acculturation: Views of Dutch and Turkish-Dutch. European Journal of Social Psychology, 33, 249-266. DOI: 10.1002/ejsp.143

Arends-Tóth, J., \& Van de Vijver, F.J.R. (2006). Assessment of psychological acculturation. In Sam, D.L. \& Berry, J.W. (Eds.), The Cambridge handbook of acculturation psychology (pp.142-162). Cambridge: Cambridge University Press.

Baysu, G., Phalet K., \& Brown, R.J. (2011). Dual Identity as a two-edged sword: Identity threat and minority school performance. Social Psychology Quarterly, 74, 121-143. DOI: $10.1177 / 0190272511407619$

Baysu, G., Phalet K., \& Brown, R.J. (2013). Relative group size and minority school success: The role of intergroup friendship and discrimination experiences. British Journal of Social Psychology, 53, 328-349. DOI: 10.1111/bjso.12035 


\section{ACCULTURATION IN THE CLASSROOM}

Berry, J.W., Phinney, J.S., Sam, D.L., \& Vedder, P. (Eds.) (2006). Immigrant youth in cultural transition: Acculturation, identity and adaptation across national contexts. Mahwah, NJ: Lawrence Erlbaum Associates.

Bourhis, R.Y., Barrette, G., El-Geledi, S., \& Schmidt, R. (2009). Acculturation orientations and social relations between immigrant and host community members in California. Journal of Cross-Cultural Psychology, 40, 443-467. DOI: 10.1177/0022022108330988

Bourhis, R. Y., Moïse, L.C., Perreault, S., \& Senécal, S. (1997). Towards an interactive acculturation model: A social psychological approach. International Journal of Psychology, 32, 369-386. DOI: 10.1080/002075997400629

Brondolo, E., Kelly, K.P., Coakley, V., Gordon, T., Thompson, S., \& Levy, E. (2005). The perceived ethnic discrimination questionnaire: Development and preliminary validation of a community version. Journal of Applied Social Psychology, 35, 335-365. DOI: 10.1111/j.1559-1816.2005.tb02124.x

Brown, R. J., Baysu, G., Cameron, L., Nigbur, D., Rutland, A., Watters, C., ... Landau, A. (2013). Acculturation attitudes and social adjustment in British South Asian children: A longitudinal study. Personality and Social Psychology Bulletin, 39, 1656-1667. DOI: $10.1177 / 0146167213500149$

Brown, R. J., \& Zagefka, H. (2011). The dynamics of acculturation: An intergroup perspective. Advances in Experimental Social Psychology, 44, 129-184. DOI: 10.1016/B978-0-12$385522-0.00003-2$

Chang, L. (2004). The role of classroom norms in contextualizing the relations of children's social behaviors to peer acceptance. Developmental Psychology, 40, 691-702. DOI: $10.1037 / 0012-1649.40 .5 .691$

Children of Immigrants Longitudinal Study (2014). University of Leuven, Belgium. [Data file]. 


\section{ACCULTURATION IN THE CLASSROOM}

Dixon, J., Durrheim, K., \& Tredoux, C. (2005). Beyond the optimal contact strategy: A reality check for the contact hypothesis. American Psychologist, 60, 697-711. DOI: 10.1037/0003-066X.60.7.697

Durkin, K., Hunter, S., Levin, K.A., Bergin, D., Heim, D., \& Howe, C. (2012). Discriminatory peer aggression among children as a function of minority status and group proportion in school context. European Journal of Social Psychology, 42, 243-251. DOI: $10.1002 /$ ejsp.870

Emonds, V., Meeus, A., Heikamp, T., \& Meulemans, B. (2014). Technical Report: Children of Immigrants Longitudinal Study (CILS) Belgium. University of Leuven, Belgium: CeSo/CSCP.

Fleischmann, F., \& Phalet, K. (2015). Identity conflict or compatibility: A comparison of Muslim minorities in five European cities. Political Psychology, DOI: 10.1111/pops.12278

Guimond, S., de la Sablonnière, R., \& Nugier, A. (2014). Living in a multicultural world: Intergroup ideologies and the societal context of intergroup relations. European Review of Social Psychology, 25, 142-188. DOI: 10.1080/10463283.2014.957578

Güngör, D., Fleischmann, F., \& Phalet, K. (2011). Religious identification, beliefs, and practices among Turkish Belgian and Moroccan Belgian Muslims: Intergenerational continuity and acculturative change, Journal of Cross-Cultural Psychology, 42, 13561374. DOI: $10.1177 / 0022022111412342$

Güngör, D., Fleischmann, F., Phalet, K., \& Maliepaard, M. (2013). Contextualizing religious acculturation: Cross-cultural perspectives on Muslim minorities in Western Europe. European Psychologist, 18, 203-214. DOI: 10.1027/1016-9040/a000162 


\section{ACCULTURATION IN THE CLASSROOM}

Haslam, S.A., Powell, C., \& Turner, J. (2000). Social Identity, self-categorization, and work motivation: Rethinking the contribution of the group to positive and sustainable organisational outcomes. Applied Psychology, 49, 319-339. DOI:10.1111/14640597.00018

Heath, A., Rothon, C., \& Kilpi, E. (2008). The Second Generation in Western Europe: Education, unemployment and occupational attainment. Annual Review of Sociology, 34, 211-235. DOI:10.1146/annurev.soc.34.040507.134728

Hewstone, M. (2015). Consequences of diversity for social cohesion and prejudice: The missing dimension of intergroup contact. Journal of Social Issues, 71, 417-438. DOI: 10.1111/josi.12120

Hornsey, M.J. \& Hogg, M.A. (1999). Subgroup differentiation as a response to an overlyinclusive group: A test of optimal distinctiveness theory. European Journal of Social Psychology, 29, 543-550

Hox, J. (2010). Multilevel analysis: Techniques and applications (2nd ed.). Hove, England: Routledge.

Kalter, F., Heath, A.F., Hewstone, M., Jonsson, J.O., Kalmijn, M., Kogan, I., \& Van Tubergen, F. (2014). Children of Immigrants Longitudinal Survey in Four European Countries (CILS4EU)-Full version. Data file for on-site use. GESIS Data Archive, Cologne, ZA5353 Data file Version 1.1.0. DOI:10.4232/cils4eu.5353.1.1.0.

Kiang, L., Harter, S., \& Whitesell, N.R. (2007). Relational expression of ethnic identity in Chinese Americans. Journal of Social and Personal Relationships, 24, 277-296. DOI:10.1177/0265407507075414

Killen, M., Mulvey, K.L., \& Hitti, A. (2013). Social exclusion in childhood: A developmental intergroup perspective. Child Development, 84, 772-790. DOI: 10.1111/cdev.12012 


\section{ACCULTURATION IN THE CLASSROOM}

Killen, M., Rutland, A., Abrams, D., Mulvey, K.L., \& Hitti, A. (2013). Development of intra- and intergroup judgments in the context of moral and social-conventional norms. Child Development, 84, 1063-1080. DOI: 10.1111/cdev.12011

Kindermann, T.A. (2007). Effects of naturally-existing peer groups on changes in academic engagement in a cohort of sixth graders. Child Development, 78, 1186-1203. DOI: 10.1111/j.1467-8624.2007.01060.x

Nesdale, D., Maass, A., Durkin, K., \& Griffiths, J. (2005). Group norms, threat, and children's racial prejudice. Child Development, 76, 652-663. DOI: 10.1111/j.14678624.2005.00869.x

Martinovic, B., \& Verkuyten, M. (2011). Dual identity among Turkish immigrants: Meaning, conditions and consequences. Utrecht: Ercomer.

Meeussen, L., Otten, S., \& Phalet, K. (2014). Managing diversity: How leaders' multiculturalism and colorblindness affect work group functioning. Group Processes \& Intergroup Relations, 17, 629-644. DOI: 10.1177/1368430214525809

Mok, A., Morris, M., Benet-Martinez, V., \& Karakitapoglu-Aygun, Z. (2007). Embracing American culture: Structures of social identity and social networks among firstgeneration biculturals. Journal of Cross-Cultural Psychology, 38, 629-635. DOI: $10.1177 / 0022022107305243$

Muthén, L. K. \& Muthén, B. O. (1998-2012). Mplus User's Guide. Seventh Edition. Los Angeles, CA: Muthén \& Muthén

Phalet, K., Baysu, G., \& Van Acker, K. (2014). Ethnicity and migration in Europe. In: X. Chryssochoou, J. Berry (Eds.), Encyclopedia Social and Behavioral Sciences (Area 2), Section 2.4 Social Psychology, Entry 24040. (forthcoming). 


\section{ACCULTURATION IN THE CLASSROOM}

Phalet, K., \& Kosic, A. (2006). Acculturation in European societies. In: D. Sam, J. Berry (Eds.), The Cambridge handbook of acculturation. Cambridge: Cambridge University Press, 331-348.

Piontkowski, U., Rohmann, A., \& Florack, A. (2002). Concordance of acculturation attitudes and perceived threat. Group Processes \& Intergroup Relations, 5, 221-232. DOI: $10.1177 / 1368430202005003003$

Platt, B., Kadosh, K.C., \& Lau, J.Y.F. (2013). The role of peer rejection in adolescent depression. Depression and Anxiety, 30, 809-821. DOI: 10.1002/da.22120

Rubin, K.H., Bukowski, W.M., \& Parker, J.G. (2006). Peer interactions, relationships, and groups. In W. Damon \& R.M. Lerner (Editors-in-Chief) \& N. Eisenberg (Vol. Ed.), Handbook of child psychology: Vol. 3. Social, emotional, and personality development (6th ed., pp. 571-645). New York, NY: Wiley.

Rutland, A., Cameron, L., Jugert, P., Nigbur, N., Brown, R., Watters, C., ... Le Touze, D. (2012). Group identity and peer relations: A longitudinal study of group identity, perceived peer acceptance, and friendships amongst ethnic minority English children. British Journal of Developmental Psychology, 30, 283-302. DOI: 10.1111/j.2044835X.2011.02040.x

Rutland, A., Cameron, L., Milne, A., \& McGeorge, P. (2005). Social norms and selfpresentation: Children's implicit and explicit intergroup attitudes. Child Development, 76, 451-466. DOI: 10.1111/j.1467-8624.2005.00856.x

Rutland, A., \& Killen, M. (2015). A developmental science approach to reducing prejudice and social exclusion: Intergroup processes, social-cognitive development, and moral reasoning. Social Issues and Policy Review, 9, 121-154. DOI: 10.1111/sipr.12012 


\section{ACCULTURATION IN THE CLASSROOM}

Sam, D.L., \& Berry, J.W. (2010). Acculturation: When individuals and groups of different cultural backgrounds meet. Perspectives on Psychological Science, 5, 472-481. DOI: $10.1177 / 1745691610373075$

Sassenberg, K., Matchke, C., \& Scholl, A., (2011).The impact of discrepancies from ingroup norms on group members' well-being and motivation. European Journal of Social Psychology, 41, 886-897. DOI: 10.1002/ejsp.833

Smith, H.J., \& Leach, C.W. (2004). Group membership and everyday social comparison experiences. European Journal of Social Psychology, 34, 297-308. DOI: 10.1002/ejsp.198

Umaña-Taylor, A.J., Quintana, S.M., Lee, R.M., Cross, W.E., Jr., Rivas-Drake, D., Schwartz, S.J., ... Ethnic and Racial Identity in the 21st Century Study Group. (2014). Ethnic and racial identity revisited: An integrated conceptualization. Child Development, 85, 21-39. DOI: $10.1111 /$ cdev.12196

Van Acker, K., \& Vanbeselaere, N. (2012). Heritage culture maintenance precludes host culture adoption and vice versa: Flemings' expectations of Turks' acculturation behavior. Group Processes \& Intergroup Relations, 15, 133-145. DOI: $10.1177 / 1368430211417263$

Verkuyten, M., \& Martinovic, B. (2012). Immigrants' national identification: Meanings, determinants, and consequences. Social Issues and Policy Review, 6, 82-112. DOI: 10.1111/j.1751-2409.2011.01036.x

Verkuyten, M., Thijs, J., \& Sierksma, J. (2014). Majority children's evaluation of acculturation preferences of immigrant and emigrant peers. Child Development, 85, 176-191. DOI: 10.1111/cdev.12111 


\section{ACCULTURATION IN THE CLASSROOM}

Verkuyten, M., \& Yildiz, A.A. (2007). National (dis)identification, and ethnic and religious identity: A study among Turkish-Dutch Muslims. Personality and Social Psychology Bulletin, 33, 1448-1462. DOI: 10.1177/0146167207304276

Vertovec, S. (2007). Super-diversity and its implications. Ethnic and Racial Studies, 30, 10241054. DOI: $10.1080 / 01419870701599465$

Voas, D., \& Fleischmann, F. (2012). Islam moves west: Religious change in the first and second generation. Annual Review of Sociology, 38, 525-545. DOI: 10.1146/annurevsoc-071811-145455

Ward, C., \& Kennedy, A. (1994). Acculturation strategies, psychological adjustment, and sociocultural competence during cross-cultural transitions. International Journal of Intercultural Relations, 18, 329-343. DOI: 10.1016/0147-1767(94)90036-1

Wentzel, K. (2009). Peers and academic functioning at school. In K. H. Rubin, W. M., Bukowski, \& B. Laursen (Eds.), Handbook of Peer Interactions, Relationships, and Groups (pp. 531-547). New York: The Guilford Press. 


\section{Footnotes}

1. Adoption of the Belgian majority culture is greatly stressed in the overriding public discourse (Van Acker \& Vanbeselaere, 2012). While some acculturation researchers assess contact, in place of adoption, we choose to measure adoption, given the strong adoptionfocus in the Belgian assimilationist climate.

2. Marginalization is treated as a residual category in the present research because its substantive meaning is unclear (Berry et al., 2006).

3. We use data from all consenting participants in randomly sampled classes from years 1,2 and 3 of 50 high schools with $\geq 40 \%$ Belgian majority youth (using as sampling criterion administrative school-level data on the percentage of pupils with 'no foreign language spoken at home'). Schools with lower rates of majority Belgians were excluded from our study sample to ensure that acculturation questions of 'adopting the Belgian customs' were a relevant matter in peer relations.

4. Other minorities' ( $N=1087)$ ethnic origins: W. Europe $N=179$ (13 countries); E. Europe $N=171$ (17 countries); Asia/Russia/Oceania N=92 (15 countries); Africa N=69 (21 countries); Americas $N=40$ (11 countries); Middle East $N=55$ (12 countries); unspecified other $N=481$. 5. We tested 2-level models with either classroom or school at the second level. Results remained largely the same. Results are available upon request from the first author. We also tested for differences between Turkish and Moroccan minority groups (using a dummy variable); this effect was non-significant in both models ( $p s>.17$ ) and it did not affect the results.

6. We also tested this third step (minority preferences only model) without moderation effects for percentage of Turkish and Moroccan minority youth in class, which yielded similar model fit $(-2 L L=687.20 ; \mathrm{AIC}=707.20 ; \mathrm{BIC}=748.72)$ and improvement $\left(\Delta \chi^{2}(3)=170.57, p<.001\right)$. 


\section{ACCULTURATION IN THE CLASSROOM}

As we were interested in testing whether our hypothesized effects generalized across

classrooms with different compositions, moderation effects were included in all models. 


\section{ACCULTURATION IN THE CLASSROOM}

\section{Table 1}

Table 1. MLR Regression Models of Own Acculturation Preferences and 'Peer' Acculturation Norms' Effects on Peer Rejection.

\begin{tabular}{|c|c|c|}
\hline & $\begin{array}{c}\text { Model 1: } \\
\text { Cross-ethnic } \\
\text { Peer Norms }\end{array}$ & $\begin{array}{c}\text { Model 2: } \\
\text { Co-ethnic } \\
\text { Peer Norms }\end{array}$ \\
\hline & $\mathrm{B}(\mathrm{SE})$ & $\mathrm{B}(\mathrm{SE})$ \\
\hline \multicolumn{3}{|l|}{ Fixed Parameters } \\
\hline Intercept & $1.61(.29)^{* * *}$ & $1.95(.32)^{* * *}$ \\
\hline$\%$ Turkish \& Moroccan Minorities in Class (\%TM) & $0.34(.18)$ & $0.35(.17)^{*}$ \\
\hline \% All Minorities in School (\%M) & $-0.03(.05)$ & $-0.07(.05)$ \\
\hline Gender & $0.02(.05)$ & $0.05(.05)$ \\
\hline Age & $-0.01(.02)$ & $-0.03(.02)$ \\
\hline Vocational track & $-0.09(.06)$ & $-0.10(.06)$ \\
\hline Own Maintenance (OwnM) & $0.02(.03)$ & $0.01(.03)$ \\
\hline Own Adoption (OwnA) & $-0.02(.03)$ & $-0.02(.02)$ \\
\hline OwnA*OwnM & $-0.02(.03)$ & $-0.03(.02)$ \\
\hline Peer Maintenance (PeerM) & $0.14(.07)^{*}$ & $0.08(.05)$ \\
\hline Peer Adoption (PeerA) & $0.16(.07)^{*}$ & $0.03(.04)$ \\
\hline OwnM*PeerM & $0.08(.12)$ & $-0.06(.04)$ \\
\hline OwnA*PeerA & $-0.09(.17)$ & $-0.04(.04)$ \\
\hline OwnM*PeerA & $0.16(.12)$ & $0.06(.04)$ \\
\hline OwnA*PeerM & $-0.11(.12)$ & $0.09(.04)^{*}$ \\
\hline OwnA*OwnM*PeerM & $0.17(.11)$ & $0.01(.03)$ \\
\hline OwnA*OwnM*PeerA & $0.34(.16)^{*}$ & $0.02(.03)$ \\
\hline Residual Variance & $0.24(.03)^{* * *}$ & $0.23(.03)^{* * *}$ \\
\hline$R^{2}$ & $0.10(.04)^{* *}$ & $0.11(.04)^{* *}$ \\
\hline
\end{tabular}

${ }^{*} p \leq .05 .{ }^{* *} p \leq .01 .{ }^{* * *} p \leq .001$

Model 1: 'Peer' = Cross-ethnic peer norms; Model 2: 'Peer' = Co-ethnic peer norms.

Note: Models present unstandardized regression results with standard errors in parentheses. Reference categories for categorical control variables are: gender $(0=$ male), school track (vocational $=0$; academic, technical, art-based $=1$ ). Moderation effects of \%TM were included in both models, but only significant effects are reported in the text for simplicity (all information available from first author upon request). 
Figure 1

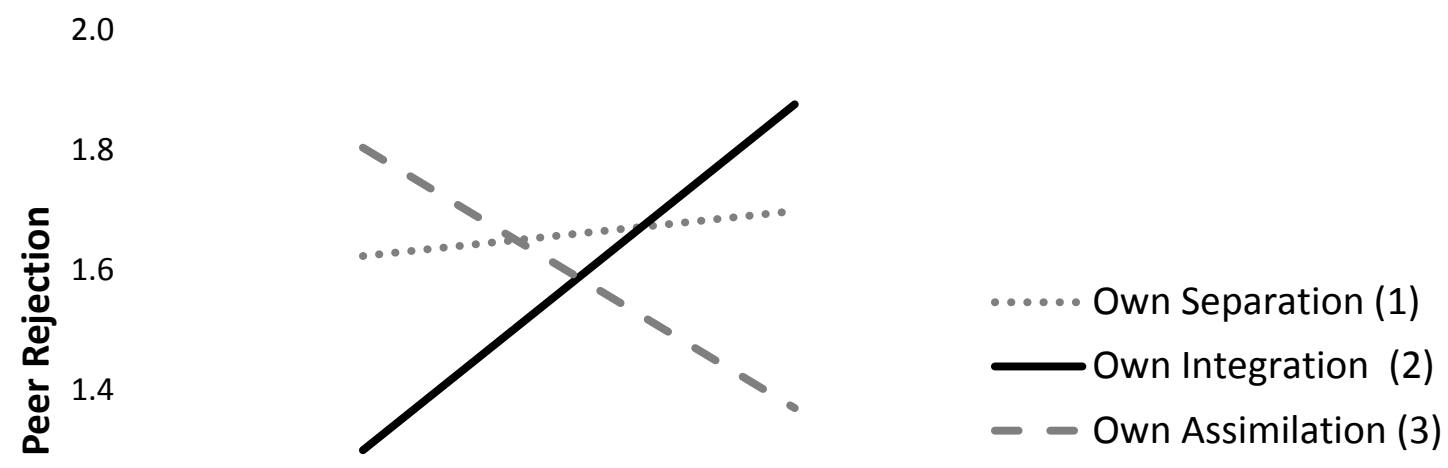

1.2

1.0

$-1 \mathrm{SD} \quad+1 \mathrm{SD}$

Cross-ethnic Peer Adoption Norms

Figure 1. Minority adolescents' own acculturation preferences predicting their experience of peer rejection as a function of cross-ethnic peer norms of adoption.

NOTE: For ease of interpretation we describe the simple effects of the 3-way interaction (own adoption*own maintenance*cross-ethnic adoption) using Berry's acculturation strategies: (1) Own Separation = +1SD culture maintenance, -1SD adoption; (2) Own Integration= +1SD culture maintenance, +1 SD adoption; (3) Own Assimilation = -1SD culture maintenance, $+1 S D$ adoption. 
Figure 2

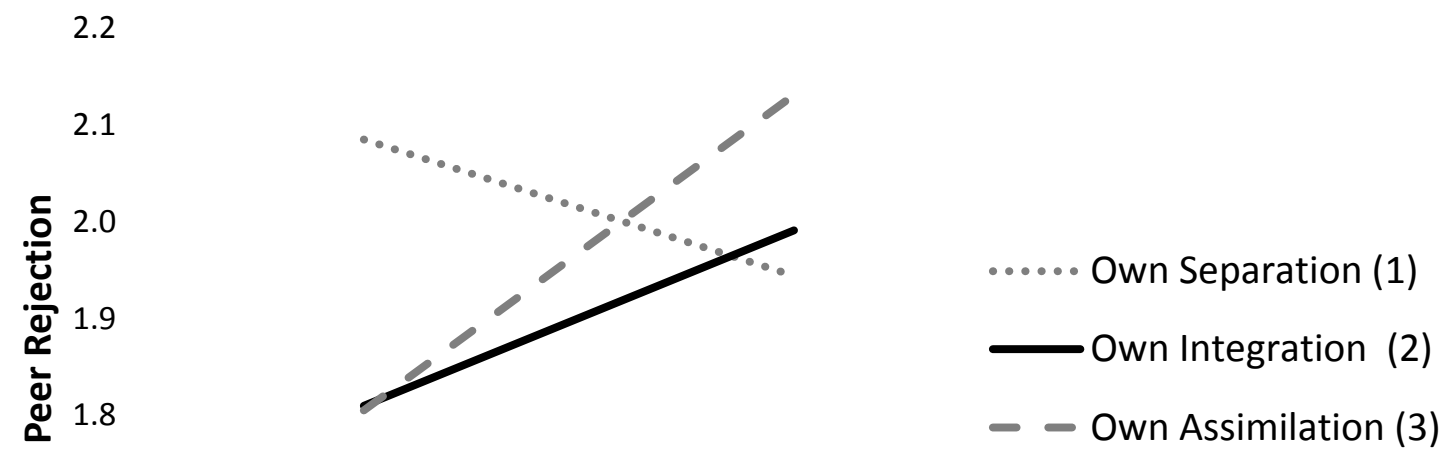

1.7

1.6

$$
-1 \text { SD } \quad+1 S D
$$

Co-ethnic Peer Maintenance Norms

Figure 2. Minority adolescents' own acculturation preferences predicting their experience of peer rejection as a function of co-ethnic peer norms of maintenance.

NOTE: This graph describes distinct minority acculturation preferences in the presence of weak vs. strong co-ethnic maintenance norms. The significant differences in this graph are driven by the significant 2-way interaction (own adoption*co-ethnic maintenance). For ease of interpretation we describe the effects using Berry's acculturation strategies: (1) Own Separation = +1SD culture maintenance, -1SD adoption; (2) Own Integration= +1SD culture maintenance, +1SD adoption; (3) Own Assimilation = -1SD culture maintenance, +1SD adoption. 


\section{ACCULTURATION IN THE CLASSROOM}

Appendix 1

Means, Standard Deviations, and Correlations $(N=681)$

$M(S D) \quad 1 \quad 2$

1. Turkish and Moroccan
$\quad$ Minorities in Class (\%TM)

2. Minorities in School $2.61(0.66) \quad .46^{* * *}$

3. Gender $48.6 \%(0.50) \quad-.01 \quad .04$

4. Age

5. Vocational Track

$15.09(1.22) \quad .09^{*} \quad .07 \quad .06$

$37.6 \%(0.49) \quad-.23^{* * *} \quad-.23^{* * *}-.07 \quad-.13^{* * *}$

6. Own Maintenance

$2.52(1.03) \quad .14^{* * *} \quad .06 \quad-.12^{* *}-.03 \quad-.14^{* *}$

7. Own Adoption

$\begin{array}{lllllll}2.82(0.96) & -.02 & .03 & .06 & -.06 & -.03 & .16^{* * *}\end{array}$

8. Cross-ethnic Maintenance

$\begin{array}{llllllll}3.17(0.52) & .54^{* * *} & .44^{* * *} & .05 & -.02 & -.35^{* * *} & .14^{* * *} & .07\end{array}$

9. Cross-ethnic Adoption

$\begin{array}{llllllll}3.38(0.51) & -.35^{* * *} & -.31^{* * *} & -.07 & -.14^{* * *} & -.02 & .02 & .04\end{array}$

$\begin{array}{llllllll}3.49(0.67) & .06 & .08^{*} & -.05 & -.05 & -.01 & .13^{* *} & .03\end{array}$

10. Co-ethnic Maintenance

$2.95(0.80)$

.05

$.03-.10^{*}$

$-.05$

$\begin{array}{lll}-.10^{*} & .09^{*} & .01\end{array}$ $-.22^{* * *}$

11. Co-ethnic Adoption

$1.34(0.57)$

.06

$.01 \quad-.06$

$-.09^{*}-.15^{* * *}$

$.05 \quad .04$

$.10^{*}$

${ }^{*} p \leq .05 .{ }^{* *} p \leq .01 .{ }^{* * *} p \leq .001$

Reference categories for categorical control variables: gender $(0=$ male), school track (vocational = 0 ; academic, technical, art-based = 1). 